\title{
Conflict Management Coaching's Place in Community Mediation: A Value Added Service
}

\section{Merle D. Rockwell and Edward G. Modell}

\begin{abstract}
This article discusses a pilot project that enabled a community mediation centre to also offer conflict management coaching services when it was not possible to bring both parties into mediation or when one of the parties was seeking a better way to address a dispute. The authors, experienced professional mediators and credentialed coaches, explain in detail how they developed and delivered a training programme in coaching skills for a group of the centre's volunteer mediators. The programme consisted of 16 hours of in-person training followed by virtual role-plays and mentoring together with quarterly in-person refresher trainings. Surveys of mediators who received the training and clients who received the coaching services showed that the project was highly successful, which the authors also attributed to the commitment of the centre's leadership, staff and volunteers.
\end{abstract}

\section{Keywords}

Mediation, coaching, conflict management

\section{Introduction of the Programme}

Thinking about our community mediation centre's tag line "strengthening our communities, peace by peace" and our mission of "promoting and providing collaborative problem solving processes throughout our county," it was apparent that something was missing. Since mediation was the primary ADR process we offered, we had nothing to offer when mediation wasn't possible because the other party was unwilling to "come to the table". There was no one on our staff or volunteer roster who had the skills to work one-on-one with a person to help them manage their conflict differently. Similarly, the centre mediators were not able to help someone who turned to us for help managing conflict that arose in the implementation of a mediated agreement, or to help someone prepare for mediation when we were asked to do so. Referrals to other agencies offered an easy remedy when conflict resolution really wasn't the issue. But what about those who were left holding onto all the conflicted and angry feelings?

These questions were part of a daily concern for the Executive Director of a community based conflict resolution 
centre in Montgomery County, Maryland, USA. We, as experienced mediators who were additionally trained as executive coaches, wondered how to fill this gap in service. Could coaching be a meaningful adjunct to a mediation practice: to prepare for mediation, or to deal with their conflicts in situations where traditional mediation services could not be used, or to assist them in resolving conflict involving the implementation of a mediated agreement? Using a process of asking strategic and powerful questions, we knew that coaches could help someone explore their conflict situation from their own viewpoint and then, somewhat more challenging, from the other person's viewpoint. After many years of mediating, we sensed that the more personal touch allowed by coaching might really make a difference in helping people articulate their interests in the conflict and explore new ways of managing their response.

There is a community based mediation centre in 17 of the 23 counties in the state of Maryland. These centres are funded through performance based grants from the Maryland Judiciary as well as other grants and donations. Generally, they hold non-profit status and are designed to serve an often underserved part of the population in order to give equal access to ADR processes. Consequently, they do not charge for most of their services. While the basic service offered is mediation, each centre has the autonomy to offer additional services such as group facilitation and restorative justice circles. Some centres are free standing; others may be housed on a college campus or state or local municipal government office building.

The Carroll County Community Mediation Centre (CCCMC) offers mediation services for:

- Neighbourhood: between neighbours, neighbourhood organizations, youth-adult neighbourhood conflicts and landlord/tenant disputes.

- Family: parents and their teenage child/children, sibling conflicts, parenting plans (custody and visitation agreements), caring for an elderly family member, husband and wife conflicts and veterans returning from service transitioning back into the family.

- Interpersonal: strained relationships and friendships, roommate disputes, conflicts between boyfriend and girlfriend or partners.

- Business: employment disputes, conflicts between co-workers, businesses and their customers and, businesses and their surrounding neighbours.

- Schools: students and teachers, students in conflict with each other and, parents in conflict with the school.

- Justice System: conflicts where police have been called, where criminal charges have been filed for a misdemeanour crime or when people are leaving prison and dealing with conflict with family and/orfriends.

- Referrals: from other agencies.

Because of our own experience as mediators and coaches, we knew that we could successfully bring the two fields together. Through a series of phone conversations or face to face meetings, as conflict management coaches we knew we could help someone prepare for and/or deal with a difficult situation. As conflict coaches, we used a combination of mentoring, skill-building, planning and coaching to assist others to become more 
effective in dealing with interpersonal conflict in both the workplace, the community and at home.

We wondered whether mediators could be taught basic coaching skills to help Party \#1 change their perspective on the conflict, to prepare for mediation and/or to most effectively implement a mediated agreement? We wondered whether, given an opportunity for a one-on-one supportive, coach-like conversation with a trained mediator/coach, there was the possibility of shifting the way people approached their conflict that would then allow them to manage it in a different way. Mediation cannot occur without at least two parties being present. By its nature of neutrality, the mediator does not engage one of the parties and while there may be ample opportunity to explore the "other's" perspective, this cannot happen unless the other is present and willing to engage. What makes coaching different from mediation is the personal interaction between the coach and the participant.

As Conflict Coaches we help someone:

- Examine the ways in which they currently approach conflict and helpexplore new ideas.

- Look at alternate perspectives.

- Expand the ways in which someone responds to conflict.

- Gain new skills.

- Build on a person's strengths.

- Become more comfortable and confident in dealing with conflict.

- Create an action plan based on what's most important for the person and is in line with their values.

- Take action and follow through on their plans.

- Prepare for difficult meetings

How is his done?

- By listening at a deep level.

- Asking provocative questions.

- Challenging self-limiting ideas.

- Providing support, encouragement and encouraging new ideas.

- Working from the premise that each of us is naturally creative, resourcefuland whole.

It seemed that designing and finding a way to implement a pilot programme made sense as a way to see if we were right in our assumption that conflict management coaching could serve as an adjunct or a positive alternative to mediation. A training course in coaching was developed and offered to staff and volunteer mediators in order to test this assumption. Along with the training, participants would receive mentoring in the use of coaching techniques. An evaluation instrument was also designed to assess whether the introduction and use of coaching produced meaningful results for the mediator/coaches and their clients.

During 2012 the CCCMC in Maryland was selected to pilot the Conflict Management Skill Training for 
Mediators. Critical in choosing which of the many Maryland based community mediation centres would probably work best for the pilot programme was having an Executive Director who was somewhat familiar with coaching and was entirely supportive of being a part of and promoting this initiative.

We had tried this with several other communities based mediation centres. Our first effort was to train credentialed coaches in conflict resolution skills. This was an eight (8) hour training offered to participating coaches at no charge. They in turn, agreed to volunteer eight (8) hours of conflict management coaching to the participating centres.

It did not work very well. None of the three (3) Executive Directors was fully committed to seeing it work and the training was not long enough to assure sufficient skill building so that the coaches felt comfortable dealing with conflict in this way. Interestingly, we also found that many of the coaches were conflict averse, which we had not accounted for in the design of our training. In hindsight, it might have had a better outcome if we had spent time exploring their different conflict styles and strategies for managing their own responses to conflict.

To that end, and in response to the lessons learned from those earlier attempts, the coaching training course offered in this pilot programme included 4 hours of "Understanding Conflict Styles - using the ThomasKilmann Conflict Model" instrument (1974). Taking the time to add this into the early part of the CCCMC training proved to be advantageous in that it increased the confidence of the mediators to recognize different styles and to respond in a more constructive way.

There are "crossover" skills shared by mediation and coaching which is why blending the two can often work well. Some common skills are: recognizing that the agenda comes from the "client" and focusing on what they want out of the engagement, active listening and reframing, and problem-solving. Mediation and coaching are each grounded in the basic premises of self-determination and confidentiality. Perhaps the biggest difference is in the more closely aligned working relationship that exists in coaching as opposed to mediation. Interestingly, however, having trained coaches in conflict management skills and mediators in coaching skills, we found it easier to train coaches. This was primarily due to their professional coach training which includes building an alliance with the person they are coaching. This, of course, cannot happen in mediation between parties if the mediator is to remain neutral.

The following is a summary of some of the similarities and differences between conflict coaching and mediation.

\section{Mediation}

1. Goal: To reach partial or total agreement or to improve communicationskills.

2. Training: minimum usually 40 hours basic plus specialization courses

3. Structured conversation with parties in conflict with third party neutralfacilitating.

4. Voluntary and confidential.

5. Almost always done in person. 
6. Mediator is neutral.

7. Conflict exists.

8. Active listening and reframing

9. Open ended questions.

10. Do not normally engage in role playing during mediation

\section{Conflict Coaching}

1. Goal: To resolve a dispute (past, present or anticipated), prevent an unnecessary dispute, prepare for a conflict conversation or generally improve competency in conflict management.

2. Training and credentialing: minimum 60 hours plus 100 hours of coaching clients for ACC level with additional, specialized training.

3. Coach forms an alliance with and acts as a supporter of the client (usually one-on- one although group coaching is possible).

4. Voluntary and confidential.

5. Done in person or virtually

6. Agenda comes from client - coach partners with client.

7. Conflict exists or skill building for the future; or as a process that can be used in preparation for, following or in place of mediation.

8. Active listening and reframing.

9. Powerful, open ended questions.

10. Use of role play of possible interactions with clients. Conflict coaching is a sub- specialty of coaching, requiring additional training.

The approach employed for most seeking services in the CCCMC programme involved helping them find a new perspective on the conflict they found themselves in or to develop a confidence that they could identify and stand up for their interests in this and future conflicts. When asked "What is this really all about?" the coaches help the other person peel back the layers, so to speak, to get at their core concerns. Often in doing so, it was discovered that it was something different than what had initially been presented. As noted earlier, individuals seeking coaching may want to work on ways to prevent a dispute from unnecessarily escalating, to improve their competency in conflict management, to develop stronger communication skills for a difficult conversation and other objectives that are often more about managing, than resolving an issue. In conflict management coaching, individuals hopefully learn to handle their own issues with others, and to approach dispute situations with more self-awareness and skill.

In designing the coaching process and the training curriculum, we were aware that most mediators were familiar with a step-by-step process of mediation. To that end, we designed the following six step process that closely resembled the process we had learned to use when trained as coaches: 
Step \#1 Establishing the Coaching Relationship

Step \#2 Exploring the Client’s Current Story

Step \#3 Clarifying the Client's Goals or Desired Outcome Step \#4 Identifying Different Perspectives

Step \#5 Creating a New Story

Step \#6 Forwarding the Action - Deepen the Learning.

Appendix A outlines these steps in a little more detail.

We worked closely with the Executive Director of CCCMC to design the conflict management coaching pilot programme for mediators which included who and how we would select the mediators to train. We knew that not all of CCCMC's volunteer mediators were interested in a process that differed from mediation and required one- on-one contact, including contact that might often be virtual (by phone, Skype, Zoom or other modality). Once the opportunity was described and the required commitment explained, mediators who wanted to participate were each interviewed by the Executive Director.

Before making a commitment to participate, the mediators were told they would be required to: attend the initial 16-hour training; engage in additional role plays by phone with the instructors who would assess their readiness to coach; attend quarterly 5-hour skill refresher workshops that would also address any problems or issues that arose in the use of coaching; and, make themselves available when called upon to provide the service. The interview with each candidate was important in order to determine those who were truly committed to the project. As a result of the interview process, there were 14 mediators willing and ready to be trained.

A key to success of the pilot programme would be the adequacy and ease of the Centre's intake people to explain the service that was offered. Therefore, the intake people were included in the initial training and participated in an additional training specifically addressing the intake process. The goal here was for them to be able to succinctly explain the services offered and be able to answer questions from prospective users.

In planning the pilot programme, we as the organizers and trainers believed it would be naive to assume that everyone "gets it" after a one-off training. Therefore, we designed and provided four quarterly follow-up trainings to be held in the 12 months following the initial training. During those trainings, the mediator/coaches raised whatever concerns they had about their own performance, questions about "what should I do if....", skills the mediator/coaches felt needed more development and, role plays with observers who knew how to give constructive feedback. In our roles as trainers and mentors, we also provided continuous mentorship and support for the 14 mediator/coaches initially trained in 2012. Several of the mediator/coaches contacted us before coaching sessions seeking support and a boost to theirconfidence.

\section{Evaluating the Programme}

Working collaboratively with the CCCMC Executive Director, we gathered feedback each quarter in the form of written evaluations from the volunteer coaches then used their responses to design the next follow-up 
refresher training. This information from the participants allowed us to work diligently and thoughtfully to address the mediator/coaches' ongoing needs. By continually seeking their feedback and using that information to create further training sessions, it also encouraged them to take "ownership" of their learning.

After recruiting, interviewing, selecting, and training volunteers in 2012, the Centre designed, created and maintained a database to capture pertinent data to be used to assess and later evaluate the pilot project. The data was collected in several different ways in a manner agreed upon and designed by us in collaboration with the Executive Director. It included:

- Number of people who were offered coaching services

- Number of people who accepted coaching services

- Number of people who accepted coaching and did not receive coaching services

- Number of people who received and completed coaching services

- Number of coaching sessions completed

- Number of completed 7-day post coaching surveys

- Number of completed 3-month post coaching surveys.

See Appendix B for Client Evaluation Form.

Overall, the feedback was very positive on both occasions it was used. The percentage of participants' positive responses increased when surveyed at three months for every question except one which remained the same at 100\% (agreed they "would recommend coaching to others"). In fact, participants responded 100\% "strongly agree" and "agree" to all of the questions. We believed this might be due to the opportunity of time to practice new skills.

Since July 2012, the Centre has consistently offered conflict management coaching services to clients, provided case management and volunteer coordination by assigning, coordinating and following up with volunteer mediator/coaches who have conducted coaching sessions throughout the year, completed and submitted case follow up sheets to the Centre in a timely manner, participated in four follow up practice coaching sessions, and utilized the support of the trainers. The Centre has since designed, created and conducted 7 days and 3 month surveys with coachingparticipants.

We worked with the Centre to set up goals that would be a way to measure the success of the pilot programme. We suggested that the goals be written in a present perfect statement so that they could be envisioned as successes.

Goal 1: A newly designed conflict management coaching process is developed and implemented. This programme in its current iteration was designed specifically for this learning audience for all of the reasons cited earlier. There was no such programme available from which to "borrow" in whole or in part. It is unique.

Goal 2: Our staff and volunteers feel supported and competent in providing conflict management coaching services in Carroll County. Using written evaluations completed by staff and volunteers at the completion of the two-day training and after each quarterly follow-up allowed us to track and adjust the skill 
building we were delivering from the perspective of the trainees (mediator/coaches). Making ourselves available during the pilot year for phone consultations and case role plays also help build their coaching competence.

Goal 3: $80 \%$ of citizens who use coaching services report that coaching helps them learn new ways to deal with the current and future conflict in their lives. By surveying participants at various intervals, we were able to ascertain the sustainability of their experience and if they were able to use the skills and information they had discovered during the coaching session(s).

Goal 4: CCCMC offers conflict management coaching as an additional ADR service when mediation is not possible or desired in order to address conflict.

\section{Results and Analysis}

Goal 1: The overall significance of this project is the successful addition of conflict management coaching services at the CCCMC. The results of this pilot year show that coaching is a viable conflict management process that could be integrated into any community mediation centre's menu of services if the centre leadership staff, volunteers and trainers are committed to its successful implementation. For coaching services to be truly and consistently offered to and utilized by community members as a service in and of itself there needs to be a funding stream to account for the necessary resources to provide case management and volunteer support.

Goal 2: The outcome achieved was that $90 \%$ of staff and volunteers indicated they felt prepared, supported, and competent in offering coaching services. Coaches completed evaluations after each training, including an end of year evaluation, and participated in a focus group conducted by MACRO (Maryland Mediation and Conflict Resolution Office). Analysis of the end of year evaluation responses showed that coaches, on average, rated their level of confidence at 7.75, their level of competence at 7.65 and their experience level at 7.15 (on a scale of $1=$ not at all and $10=$ very). The focus group participants' responses were overwhelmingly positive about the quality of the trainings and accessibility of Centre and trainer support and mentorship. Appendix C gives a summary of comments from the focus group.

Of the initial group of fourteen mediators, twelve mediator/coaches remained active after a 6-month period. Of the two who were not active; one moved away, and the other had a family situation which required their full attention.

Almost 18 months after the initial training, ten (10) mediator/coaches participated in the final evaluation and focus group to give their feedback on the pilot year. Analysis of evaluations shows the volunteers, on average, rated their level of confidence at 7.75, competence at 7.65, and experience at 7.25 on a scale of 1-10 (1 $=$ not and $10=$ very).

When asked what they needed to continue to volunteer and stay engaged, their responses in order of frequency were: referrals for services, support from the trainers (mentorship, accessibility), practice sessions and regular training.

While the volunteer mediators already exhibited excellent listening skills, one of the primary challenges

http://jmaca.maynoothuniversity.ie

Page | 510 
in training them as coaches was to get them to have the clients "bottom line" their stories or focus on the essential elements or points about their conflict and what they might be able to change about themselves for a satisfactory outcome. Initially, the mediators seemed to feel that they were being rude to the client when they interrupted their lengthy story-telling whereas bottom lining actually helped the client focus. One of the key training questions they learned in these situations was to ask "What's important to you about this story?"

The mediators also tended to over-reflect the client's statements rather than following the client's statements with powerful questions. Over time and multiple role play and practice sessions, the mediators became much better at these coachingskills.

Goal 3: We found $75 \%$ of coaching participants surveyed within 7 days of participating in coaching agreed coaching made a difference in how they handled the current conflict; this result was 100\% for the coaching participants surveyed 3 months after receiving coaching.

Surveyed within 7 days of participating in coaching, $88 \%$ of participants agreed the coaching process helped them determine what was important to them. This percentage increased to $100 \%$ when surveyed 3 months later.

Surveyed within 7 days of participating in coaching, 94\% of participants agreed they would use coaching again. This percentage also increased to $100 \%$ when surveyed 3 months later.

Somewhat surprising was the change in participants' willingness to use mediation. Participants surveyed 3 months after coaching were more willing to use mediation for future conflicts than they were before using coaching and $69 \%$ of coaching participants surveyed within 7 days of participating in coaching agreed coaching helped them learn new ways to address conflicts. This percentage increased to $71 \%$ when surveyed 3 months later. This was an indication that timing might be something to be considered in terms of measuring a participant's readiness to be coached.

During the pilot period, nineteen people received coaching services. Through follow- up surveys they indicated they felt heard by the coaches, the process helped them to figure out what was important to them, coaching made a difference in how they handled the current conflict, coaching helped them to learn new ways to address conflict, and they would participate and recommend coaching to others.

Goal 4: Following the pilot project, CCCMC engaged in an outreach and marketing strategy which included coaching as a stand-alone service. The marketing effort in 2014 reached at least 1500 people who were informed or educated about coaching services in Carroll County through those outreach efforts. The overall significance of this project is the successful addition of conflict management coaching services at the CCCMC. The results of this pilot year showed that coaching is a viable conflict management process that could be integrated into any community mediation centre's menu of services if the centre leadership, staff, volunteers and trainers are committed. 


\section{Additional Lessons Learned}

We learned that for coaching services to be truly and consistently offered to and utilized by community members as a service in and of itself, there needs to be a funding stream to account for the necessary resources to provide case and volunteer management. Under the current funding model for community mediation centres in Maryland, centres would be resistant to offering coaching services over mediation services because it could adversely impact grant funding levels. If conflict management coaching is marketed aggressively over time to the citizens, businesses, and organizations in the community, it could potentially be utilized more than mediation. The CCCMC continues to offer conflict management coaching to the Carroll County community as it did throughout the pilot year and intends to explore funding opportunities to sustain the programme.

The experience of the trainers in training community mediators to provide coaching services can inform and assist potential future coaching trainings for mediators. Training those who are already serving as coaches to work with clients in conflicts appears somewhat easier than training mediators in the skills of conflict management coaching, primarily because conflict management coaching is a subspecialty of professional coaching and involves a very different process and skillset than the co- mediation model used by most mediation centres in Maryland.

A challenge for any centre offering a new service is getting people to agree to use the service. The CCCMC worked hard at marketing, promoting and educating community members, organizations and businesses about conflict management coaching services throughout the pilot year. However, one thing the CCCMC says it will do differently is to pre-market the service, letting the community know it is coming. Starting to market the service after volunteers and staff were trained meant there was a time period with no referrals for newly trained mediator/coaches, which we addressed by having regular practice coaching sessions for volunteers. However, if they had been marketing the service for three months prior to starting the pilot, they would have had a better chance of having actual referrals immediately after they started offering the service.

Training of new staff members is another consideration. Volunteers come and go. Initially CCCMC staff participated in the coaching training. However, when the CCCMC experienced a change in personnel, the new staff member had not received the same benefit. Ideally, everyone (volunteers and staff) who answers the centre's phone, conducts intake, conducts outreach, or has contact with potential and past mediation participants should complete the same training as the conflict management coaches. An alternative strategy, when the full training is not feasible, is to have the staff person receive coaching services as a client and debrief with the trainers immediately afterwards. We did this when a new intake person was hired by CCCMC some months after the pilot period ended.

Upon reflection, what might make this an even richer experience in the future would be for us to videotape role-plays of the mediator/coaches so they could observe themselves and be their own critics of their newly developed skills. As trainers, we know the value of having trainees see themselves in action as they are learning. We all have preconceptions of how we are doing, whether or not those are accurate, which they usually are not. In an ideal world, we would be able to give them the valuable feedback visually and not just orally or in 
writing. This could be very powerful in anchoring the participants' learning as well as identifying areas where additional training would be useful. As of the date of this article, the CCCMC continues to offer conflict management coaching as an important value-added service.

\section{References}

Maryland Mediation \& Conflict Resolution Office http://www.courts.state.md.us/macro/

Mediate BC Blog,

http://www.mediatebcblog.com/2016/11/21/top-5-reasons-to-work-with-a-conflict- coach/

Thomas, K. W., \& Kilmann, R. H. (1974). Thomas-Kilmann Conflict Mode Instrument. Mountain View, CA: Xicom, a subsidiary of CPP, Inc.

Noble. C. (2011) Conflict Management Coaching: The CINERGYTM Model, CINERGYTM Coaching

Wright, M., Mediation \& Coaching: A Common Core, http://www.mediate.com/articles/WrightM2.cfm ; accessed (January 2016)

\section{Other Sources}

CCMC, Carroll County Community Mediation Centre: https://www.carrollcc.edu/StudentServices/Community-Mediation-Centre

International Coach Federation www.coachfederation.org

\section{Appendix A: 6-Step Conflict Coaching Management Skills Training for Mediators}

\section{Step \#1 Establishing the Coaching Relationship:}

Explain the process so that the party understands the purpose and the self-determinative nature of your role. This is when you build trust between the two of you which is critical to the success of coaching.

\section{Step \#2 Exploring the Client's Current Story;}

The purpose is to hear from the "client" about what is going on with them and for the "coach" to be listening for what is being said and what is not (level \#3 listening). Stay in a place of curiosity and help them "expand" the story by asking powerful questions. As coach, be careful not to assume or judge what is being said. You will want to be listening for these types of narratives that will give you a clue to the "perspective" the client comes with to the coaching session.

\section{Step \#3 Clarifying the Client's Goals or Desired Outcome:}

This is your opportunity to probe more deeply into what the client needs and wants and to help them recognize they are not necessarily the same thing.

\section{Step \#4 Identifying Different Perspectives;}

This is your opportunity to probe more deeply into what the client needs and wants; to identify their current perspective; to look at the conflict from different perspectives - sort of like "trying on hats", which 
opens up possibilities and options they are not able to "see" in their current perspective.

\section{Step \#5 Creating a New Story:}

Once you have listened to their story (at level 3), they have clarified their goals for this conversation and identified a perspective in which they feel most confident they can meet their goals (or at the very least move closer to them) you need to use your intuition and the information you have gathered (spoken and non-verbal) to determine what is needed here. Before you move down a specific road, check it out with your client. For instance: "It looks as though you need a little guidance on how to have that conversation?" Here are some probable "roads" (This is a metaphor).

\section{Step \#6 Forward the Action - Deepen the Learning;}

Forwarding the Action part of this last step is about "doing". Forwarding the action moves your client to do something, engages them as an active participant in the change they desire. It bursts wide open the box of what the client thought was possible, and creates new realities for the client to step into. Use the one(s) that make the most sense.

Deepen the Learning - This step focuses on the "being" of your coaching experience with this client. What have they learned? What is different for them as a result of this experience?

Appendix B: Conflict Coaching Client Survey

\section{PLEASE FILL OUT THIS SURVEY AFTER YOU HAVE COMPLETED YOUR CONFLICT COACHING SESSIONS}

\section{CONFLICT COACHING CLIENT SURVEY}

This survey asks you some questions about your experience with coaching services. Your answers will help us to improve our services. This survey is confidential. Please do not put your name anywhere on this paper. No one but the program evaluators will see your answers.

\section{When you complete this survey, please mail it in the enclosed addressed and stamped envelope.}

\section{Thank you!}

Instructions: For each statement about your experience with Conflict Coaching services, please check the box that indicates how much you agree or disagree. 


\begin{tabular}{|c|c|c|c|c|}
\hline $\begin{array}{c}\text { Strongly } \\
\text { Agree }\end{array}$ & $\begin{array}{c}\text { Somewhat } \\
\text { Agree }\end{array}$ & $\begin{array}{c}\text { No } \\
\text { Opinion }\end{array}$ & $\begin{array}{c}\text { Somewhat } \\
\text { Disagree }\end{array}$ & $\begin{array}{c}\text { Strongly } \\
\text { Disagree }\end{array}$ \\
\hline
\end{tabular}

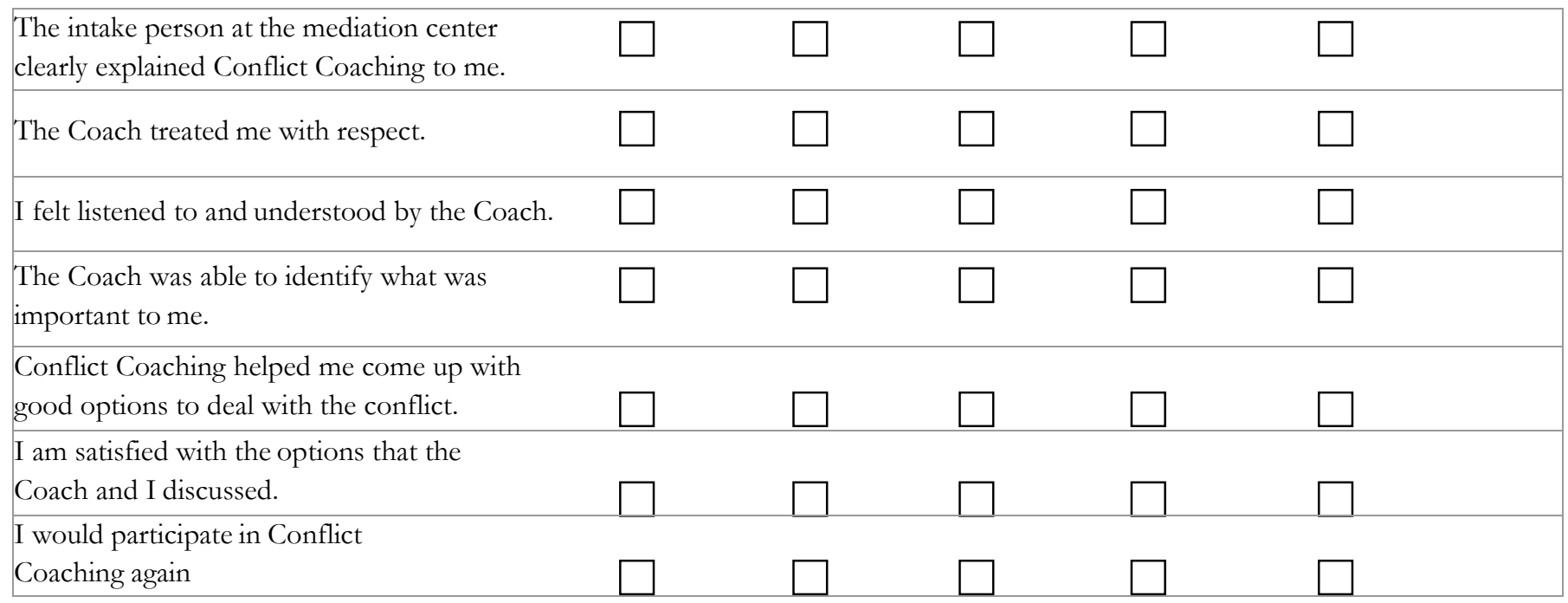

Please take a minute to answer the following questions:

\section{What would you have liked the Coach to have done differently?}

9. What was the best part of the experience you had with your Coach?

Case No. 


\section{Appendix C: Focus Group Notes from Carroll County Conflict Coaches}

June 22, 2013

Question: You had four trainings spread out over the year. What were the plusses and minuses of this approach? What would you recommend for others?

Each bullet point indicates a new person speaking.

- Have trainings spaced closer together

- Liked that it was spread out over a year. Would have liked more sessions

- Agree with previous, strengthened skills, access to Ed and Merle helpful

- Important to continue training, allowed more "a ha" moments, heard about it in training, tried it, came back for more training, fostered the "a ha" moments

- Coaching requires a lot of skill and it's also an art form, the spread out period of learning was helpful. Observe others, fishbowls, coaching us, gave us time to learn more

- Agree, built trust together, on-going help us take care of ourselves/debriefing opportunities, gave us a "sand box" to play in, try things

- Agree, two days training was so intense, "shoot me know", but somehow it all came together, spreading out helped

- At first I was scared about the two intense days, but every session built on what we learned, important to continue supporting this project, helped us master skills, learn from each other

- After two-day training some had opportunity to practice, not all people had the opportunity to coach, so people at different places for the next training. Got different things out of training, may want to consider this in scheduling first follow-up training, timing

- First training was overwhelming, facility helped (could go outside, nice place), had food, group formed, emailed between sessions, created an on-going community

- Good that we had practice session early, even if no cases, helped with learning

- Camaraderie, group formed, people we could call and talk

- Size was good, don't go too big

- Was involved - demanding - speaks volumes to quality of trainers

- Share case material before first training, allow us to become familiar with context, perhaps not as overwhelming if familiar with ideas/jargon before training

- More feedback from trainer to help us focus on areas to improve. Some others in the room pushed back on this, felt they could always call Ed and Merle 
- It was really valuable to check in with Ed and Merle, at first reluctant, didn't want to bother them, but great to work with

- Add another call in (phone) coaching simulation with Ed or Merle before end of year long training. Many people agreed with this idea, a lot of energy around it

- Second day of two-day training was very intense, anyway to spread out or have video to watch before training or webinar to make us more familiar and help ease the learning curve

\section{Question: Biggest challenges for you?}

- Getting organized initially with material before first call

- Performance anxiety, hard first two times, but good group, supportive

- Terror, how to move client forward, so different from mediation that has specific steps, and learning not to reflect so much

- Develop a level of rapport with client, really connecting, how to know what to change to connect with different people

- Bottom lining, I listened too long, I felt I need to get more information to help them move forward

- Be present, ask bottom line questions, touch on phases but don't have to be captured by phases

Question: Does this make sense in Carroll County?

- Yes! shouted by several people. So many different cases that can benefit. Referenced feedback results from participants' surveys.

Question: Should we foster elsewhere? If so, what parts?

- Wants to keep in Carroll County

- Need to have infrastructure (Centre) and support of volunteers, we had that here

- If others are looking for shortcuts, shorter trainings, less work by Centre staff, probably will not work well in those conditions, need clear expectations and dedicated folks working on it

- Could you expand us to other counties? Use us as coaches elsewhere?

- Perhaps we could serve as mentors for other counties new Conflict Coach trainees

- If this project is not priority, respected, not going to happen

- 45 minute call, can stay home, easier than going to mediation locations

- Require centres to first develop a roster of willing volunteers before they can apply for grant

- Level of commitment needed

- Work with $\mathrm{CMM}^{*}$ Question: Anything else? 
- Ed and Merle are wonderful, many agreed with this statement

- Grateful for experience

- Ed and Merle bring a lot to program

- They changed things to meet our needs

- Responsive

- Sought our input

- Center is wonderful

- Went to Tricia Jones training also, this model seems more open, help clients think in new ways

\section{Biographies}

Ed Modell and Merle Rockwell are Executive/Leadership Coaches, mediators, facilitators and trainers, with a specialty in Conflict Management Coaching. They are the principals in Balanced Coaching \& Conflict Management and presented at the 2011 and 2017 UK ICF conferences. They currently co-lead the ICF Maryland Chapter Conflict Management Coaching Community of Practice.

Deeply involved with the development and growth of the ICF both in the States and round the world, Ed is a Past President of Global ICF and of the ICF Metro DC Chapter. Merle has served on several Global ICF Committees and Task Forces, including the committee responsible for recommending the Minimum Eligibility Requirement for ICF membership. She currently serves on the Board of the ICF Maryland Chapter.

Ed and Merle's practice includes coaching leaders of NASA, the US Federal Energy Regulatory Commission and the US Department of the Interior. They also mediate cases for the Maryland Courts and facilitate strategic planning and other corporate and non- profit organization meetings.

http://jmaca.maynoothuniversity.ie 